\title{
Penentuan Karakteristik Fluida dan Estimasi Temperatur Reservoir Panas Bumi di Sekitar Gunung Talang
}

\author{
Zullinira Dwi Utami*, Ardian Putra \\ Laboratorium Fisika Bumi, Jurusan Fisika \\ Fakultas Matematika dan Ilmu Pengetahuan Alam Universitas Andalas \\ Kampus Unand LimauManis, Padang, 25163 Indonesia \\ *zullinira23@gmail.com
}

\begin{abstract}
ABSTRAK
Telah dilakukan penelitian penentuan karakteristik fluida dan estimasi temperatur reservoir panas bumi di sekitar Gunung Talang sebagai salah satu tahap awal penentuan pengembangan sistem panas bumi di Kabupaten Solok, Sumatera Barat. Penelitian mengambil sampel 12 titik mata air panas sebanyak $100 \mathrm{ml}$ di sekitar Gunung Talang. Penentuan karakteristik fluida panas bumi dilakukan menggunakan diagram segitiga Na-K-Mg dan Cl-Li-B. Diagram Na-K-Mg digunakan untuk menentukan keseimbangan fluida reservoir panas bumi. Diagram segitiga Cl-Li-B digunakan untuk menentukan asal-usul, pendidihan, dan pengenceran fluida reservoir panas bumi. Estimasi temperatur reservoir dilakukan dengan persamaan geotermometer. Pengukuran unsur $\mathrm{Na}, \mathrm{K}$, dan Mg dilakukan dengan alat Atomic Absorption Spectroscopy (AAS). Pengukuran unsur $\mathrm{Li}, \mathrm{B}$ dan $\mathrm{Ca}$ dilakukan dengan alat Inductively Coupled Plasma-Atomic Emission Spectroscopy (ICP-AES) dan pengukuran senyawa $\mathrm{SiO}_{2}$ dengan alat Visible Spectroscopy. Pengukuran unsur $\mathrm{Cl}$ dengan metode titrasi asam basa. Hasil penelitian menunjukkan bahwa semua mata air panas bumi di sekitar Gunung Talang berada pada immature water yang menandakan fluida reservoir panas bumi telah mengalami pengenceran dengan unsur lain. Fluida reservoir berasal dari sistem hidrotermal baru yang dipengaruhi oleh magma Gunung Talang. Sistem panas bumi di sekitar Gunung Talang didominasi air dan mata air panas keluar pada zona outflow. Pendidihan fluida reservoir panas bumi berada di bawah permukaan bumi hingga kedalaman sekitar 150 meter. Estimasi temperatur reservoir panas bumi dengan geotermometer silika adalah $147,63^{\circ} \mathrm{C}-179,77^{\circ} \mathrm{C}$, yang termasuk dalam sistem panas bumi bertemperatur sedang.

Kata kunci : diagram segitiga, Gunung Talang, reservoir panas bumi.
\end{abstract}

\begin{abstract}
The characteristic of fluida and estimation of reservoir temperature around Mt. Talang had been carried out as an early research for geothermal exploration in Solok Regency, West Sumatera. $100 \mathrm{ml}$ of fluids was taken from 12 hot springs in the vicinity of Mt.Talang. Determination of geothermal fluid uses the $\mathrm{Na}-\mathrm{K}-\mathrm{Mg}$ and the Cl-Li-B triangular diagram. The Na-K-Mg triangular diagram is used to determine equilibrium of geothermal reservoir fluid. The Cl-Li-B triangular diagram of is used to determinate initial, boiling, and dilution of geothermal reservoir fluid. Estimated reservoir temperature uses geothermometry equation. The $K$, and $\mathrm{Mg}$ concentrations of all samples were measured using the Atomic Absorption Spectroscopy (AAS). The Li, B and Ca concentrations were measured by Inductively Coupled Plasma-Atomic Emission Spectroscopy (ICP-AES) and $\mathrm{SiO}_{2}$ concentration was measured by Visible Spectroscopy. The $\mathrm{Cl}$ consentration was measured using the acid-base titration. The result of this research shows that all geothermal hot springs around Mt. Talang are in immature water section that indicate the geothermal reservoir fluids have been diluted with other elements. The reservoir fluid derived from the new hydrothermal system is influenced by Mt. Talang magma. The geothermal system around Mt. Talang is dominated by water and hot springs discharge in outflow zone. The boiling of geothermal reservoir fluid is below the subsurface up to about 150 meters in depth. The geothermal temperature reservoir estimated by silica geothermometer ranges from $147.63^{\circ} \mathrm{C}$ to $179.77^{\circ} \mathrm{C}$ and is included in a moderately-tempered geothermal system.

Keywords: triangular diagram, Mt. Talang, geothermal reservoir.
\end{abstract}

\section{PENDAHULUAN}

Panas bumi merupakan sumber daya panas alami yang berasal dari interaksi antara panas yang dipancarkan batuan panas dengan air. Hasil interaksi tersebut terperangkap di suatu tempat yang disebut reservoir panas bumi (Amstead dan Christopher, 1983). Menurut Direktorat Panas Bumi Kementerian Energi dan Sumber Daya Mineral Indonesia (2017) Indonesia memiliki potensi panas bumi sebesar 28.579 MW dengan total sumberdaya 11.073 MW dan total cadangan 17.506 MW. Menurut data pada website Dinas Pertambangan dan 
Energi Provinsi Sumatera Barat (2017) Sumatera Barat memiliki potensi panas bumi sebesar 1.656 MW dengan total cadangan 858 MW. Potensi Panas Bumi Sumatera Barat tersebar di Kabupaten Pasaman, Pasaman Barat, Lima Puluh Kota, Tanah Datar, Agam, Solok, dan Solok Selatan.

Kabupaten Solok, Sumatera Barat memiliki tatanan geologi yang didominasi oleh gejala tektonik berupa busur magma dan sistem Sesar Sumatera. Keduanya merupakan gejala tektonik utama yang bersifat regional, membujur sepanjang $1.650 \mathrm{~km}$ dari Aceh sampai Teluk Semangko yang dikenal dengan Sesar Semangko (Munandar dkk., 2003). Zona sesar merupakan zona lemah yang mengganggu akuifer tanah sehingga memunculkan manifestasi di daerah panas bumi (Naryanto, 1997). Zona sesar ini menyebabkan banyaknya muncul manifestasi panas bumi di sekitar Gunung Talang seperti mata air, fumarol, dan sinter karbonat (Munandar dkk., 2003). Hal inilah yang mendukung adanya potensi panas bumi di sekitar Gunung Talang. Potensi panas bumi di Kabupaten Solok yang telah terbukti terdapat pada daerah Batu Bajanjang yang masih dalam tahap sosialisasi sebelum tahap eksplorasi dan eksploitasi.

Tahap awal penentuan potensi panas bumi adalah dengan eksplorasi pendahuluan. Beberapa bagiannya adalah survei lapangan secara geologi, hidrologi, geofisika dan geokimia. Metode geokimia dapat dilakukan untuk menentukan karakteristik fluida berupa asal usul, pendidihan, pengenceran fluida serta estimasi temperatur fluida reservoir panas bumi (Saptadji, 2009). Karakteristik fluida reservoir panas bumi diperlukan sebagai salah satu indikator untuk penentuan potensi panas bumi. Penentuan karakteristik fluida reservoir panas bumi ditentukan dengan diagram segitiga dengan menganalisis sifat-sifat dasar unsur pada fluida panas bumi. Jenis-jenis fluida panas bumi ditentukan dengan diagram segitiga klorida-sulfat-bikarbonat (Cl$\mathrm{SO}_{4}-\mathrm{HCO}_{3}$ ) berdasarkan anion utama fluida yaitu $\mathrm{Cl}, \mathrm{SO}_{4}$, dan $\mathrm{HCO}_{3}$. Keseimbangan fluida panas bumi dapat ditentukan dengan diagram segitiga natrium-kalium-magnesium (Na-K-Mg) dari persentase $\mathrm{Na} / 1000-\mathrm{K} / 100-\mathrm{Mg}^{1 / 2}$. Asal usul, pendidihan dan pengenceran fluida panas bumi ditentukan dengan diagram segitiga klorida-litium-boron (Cl-Li-B) berdasarkan konsentrasi Cl/100, Li, dan B/4 dalam satuan persen (Giggenbach, 1991).

Pada penelitian ini digunakan diagram segitiga Na-K-Mg untuk menentukan keseimbangan fluida panas bumi. Pengeplotan posisi data pada diagram segitiga $\mathrm{Na}-\mathrm{K}-\mathrm{Mg}$ dapat ditentukan dengan Persamaan 1 sampai Persamaan 4. Variabel $\mathrm{S}$ adalah penjumlahan konsentrasi $[\mathrm{Na}] / 1.000,[\mathrm{~K}] / 100$, dan $[\mathrm{Mg}]^{1 / 2}$. $[\mathrm{Na}]$ adalah konsentrasi $\mathrm{Na},[\mathrm{K}]$ adalah konsentrasi $\mathrm{K}$, dan $[\mathrm{Mg}]$ adalah konsentrasi Mg. Semua konsentrasi dinyatakan dalam $\mathrm{mg} / \mathrm{kg}$ atau ppm. Menurut Giggenbach (1998) nilai $[\mathrm{Na}] / 1.000$, $[\mathrm{K}] / 100$, dan $[\mathrm{Mg}]^{1 / 2}$ didapatkan dari kesetimbangan penuh kestabilan termodinamika pada sistem mineral melalui rekristalisasi kimia atau pemurnian zat padat dari campuran atau pengotornya dengan cara mengkristalkan kembali zat tersebut setelah dilarutkan dalam pelarut yang sesuai.

$$
\begin{aligned}
& S=\left(\frac{[N a]}{1.000}\right)+\frac{[K]}{100}+\left([M g]^{1 / 2}\right) \\
& \% N a=\frac{[N a]}{(10 S)} \\
& \% K=\frac{[K]}{S} \\
& \% M g=\frac{\left(100[M g]^{1 / 2}\right)}{S}
\end{aligned}
$$

Penelitian ini juga menggunakan diagram segitiga Cl-Li-B untuk menentukan asal-usul, pendidihan, dan pengenceran fluida panas bumi di sekitar Gunung Talang. Pengeplotan posisi data pada diagram segitiga Cl-Li-B dapat ditentukan dengan Persamaan 5 sampai Persamaan 8. [Cl] adalah konsentrasi $\mathrm{Cl}$, [Li] adalah konsentrasi $\mathrm{Li}$, dan [B] adalah konsentrasi B. Semua konsentrasi dinyatakan dalam mg/kg atau ppm. Menurut Giggenbach (1998) nilai [Cl]/100, [Li], dan [B]/4 didapatkan dari kesetimbangan penuh kestabilan termodinamika pada sistem mineral melalui rekritalisasi kimia.

$$
S=\left(\frac{[C l]}{100}\right)+[L i]+\left(\frac{[B]}{4}\right)
$$




$$
\begin{aligned}
\% \mathrm{Cl} & =\frac{[\mathrm{Cl}]}{S} \\
\% \mathrm{Li} & =\left(\frac{[\mathrm{Li}]}{S}\right) 100 \\
\% \mathrm{~B} & =\left(\left(\frac{B}{4}\right) / S\right) 100
\end{aligned}
$$

Survei lapangan secara geokimia lainnya adalah estimasi temperatur reservoir. Estimasi temperatur reservoir panas bumi dilakukan sebagai salah satu indikator penentuan potensi sistem panas bumi. Metode yang dapat digunakan untuk estimasi temperatur fluida reservoir panas bumi adalah metode geotermometer, resistivitas silika, dan resistivitas air. Penelitian ini menggunakan metode geotermometer yang didasarkan pada keberadaan zat-zat terlarut pada fluida panas bumi. Metode geotermometer lebih mudah dilakukan dan telah dibuktikan di beberapa negara di dunia. Sismanto dan Andayany (2012) telah mengembangkan geotermometer empiris yang memiliki error kecil dari $5 \%$.

Geotermometer secara umum dapat dibagi 3, yaitu geotermometer silika, Na-K-Ca, dan $\mathrm{Na}-\mathrm{K}$. Geotermometer silika lebih baik digunakan pada temperatur reservoir yang tidak terlalu tinggi (Aulia, 2014). Geotermometer silika lebih baik digunakan pada fluida yang berada pada bagian immature water pada diagram segitiga Na-K-Mg (Zhang dkk, 2014). Perkembangan geotermometer silika terdapat pada Tabel 1 . Variabel C adalah konsentrasi silika (mg/L).

Tabel 1 Persamaan geotermometer silika

\begin{tabular}{lcl}
\hline \multicolumn{1}{c}{ Geotermometer } & \multicolumn{1}{c}{ Persamaan } & \multicolumn{1}{c}{ Referensi } \\
\hline Quartz-no steam loss & $\mathrm{T}=1.309 /(5,19-\log \mathrm{C})-273,15$ & Fournier (1977) \\
\hline $\begin{array}{l}\text { Quartz-maximum steam } \\
\text { loss at } 100^{\circ} \mathrm{C}\end{array}$ & $\mathrm{T}=1.522 /(5,75-\log \mathrm{C})-273,15$ & Fournier (1977) \\
\hline Quartz & $\mathrm{T}=42,198+0,28831 \mathrm{C}-3,6686 \times 10^{-4} \mathrm{C}^{2}$ & Fournier and Potter (1982) \\
& $+3,1665 \times 10^{-7} \mathrm{C}^{3}+77,034 \log \mathrm{C}$ & \\
\hline Quartz & $\mathrm{T}=53,500+0,11236 \mathrm{C}-0,5559 \times 10^{-4} \mathrm{C}^{2}$ & Arnorsson (1985) \\
& $+0,1772 \times 10^{-7} \mathrm{C}^{3}+88,390 \log \mathrm{C}$ & \\
\hline Chalcedony & $\mathrm{T}=1.032 /(4,69-\log \mathrm{C})-273,15$ & Fournier (1977) \\
\hline Chalcedony & $\mathrm{T}=1.112 /(4,91-\log \mathrm{C})-273,15$ & Arnorsson $(1983)$ \\
\hline Cristobalite & $\mathrm{T}=1.000 /(4,78-\log \mathrm{C})-273,15$ & Fournier $(1977)$ \\
\hline Opal & $\mathrm{T}=781 /(4,51-\log \mathrm{C})-273,15$ & Fournier $(1977)$ \\
\hline Amorphous silica & $\mathrm{T}=731 /(4,52-\log \mathrm{C})-273,15$ & Fournier $(1977)$ \\
\hline Sumb Aribow 2011$)$ &
\end{tabular}

(Sumber: Aribowo, 2011)

Persamaan geotermometer Na-K-Ca lebih cocok digunakan pada daerah yang mempunyai konsentrasi Ca yang lebih tinggi atau besar dari $50 \mathrm{ppm}$ (Aribowo, 2011). Geotermometer Na-K lebih cocok digunakan pada temperatur reservoir lebih besar dari $180^{\circ} \mathrm{C}$. Geotermometer ini kurang cocok digunakan pada fluida yang memiliki konsentrasi $\mathrm{Ca}$ yang tinggi (Aribowo, 2011).

Pada penelitian ini dilakukan penentuan karakteristik fluida dengan menggunakan diagram segitiga $\mathrm{Na}-\mathrm{K}-\mathrm{Mg}$ untuk menentukan kesetimbangan fluida reservoir panas bumi. Selain itu juga digunakan diagram segitiga $\mathrm{Cl}-\mathrm{Li}$-B untuk menentukan asal-usul, pendidihan dan pengenceran fluida reservoir panas bumi. Penelitian ini juga mengestimasi temperatur panas bumi di daerah sekitar Gunung Talang dengan menggunakan metode geotermometer yang sesuai dengan mata air panas tersebut.

\section{METODE}

\subsection{Persiapan Sampel}

Pada penelitian ini diambil sebanyak $100 \mathrm{ml}$ dari 12 sumber mata air panas di sekitar Gunung Talang, Kabupaten Solok, Sumatera Barat. Secara geografis, tempat pengambilan sampel dapat dilihat pada Gambar 1 yang ditunjukkan oleh variabel A sampai J. 

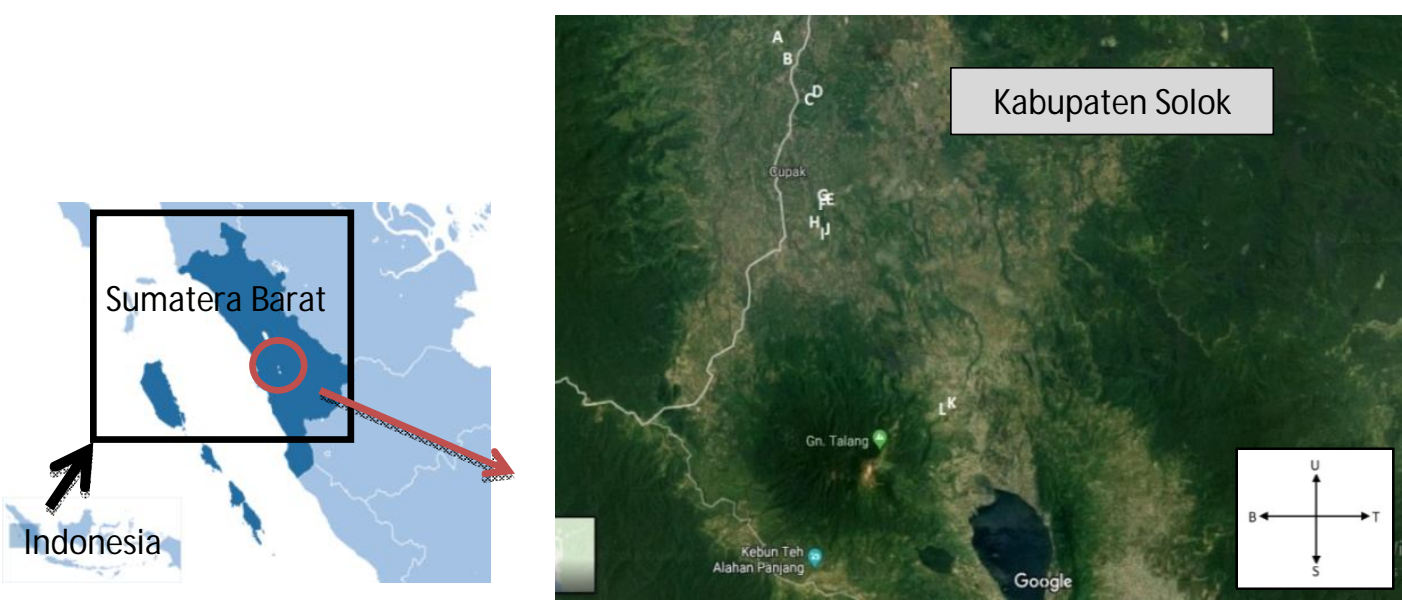

Gambar 1 Lokasi pengambilan sampel

\subsection{Pengukuran Sampel}

\subsubsection{Pengukuran temperatur permukaan dan $\mathrm{pH}$}

Temperatur permukaan air panas diukur menggunakan termometer digital. Pengukuran dilakukan langsung pada setiap sampel di lokasi penelitian. Pengukuran $\mathrm{pH}$ menggunakan $\mathrm{pH}$ meter dan dilakukan pada setiap sampel mata air panas. Pengukuran temperatur permukaan dan $\mathrm{pH}$ air panas digunakan sebagai data pendukung untuk menentukan karakteristik fluida reservoir panas bumi.

\subsubsection{Pengukuran konsentrasi sampel}

Pengukuran 12 sampel mata air panas dilakukan secara spektofotometri dengan alat Atomic Absorption Spectroscopy (AAS) di laboratorium. Pengukuran ini untuk mengetahui konsentrasi Na, K, dan Mg. Setelah itu dilakukan pengukuran sampel secara spektofotometri dengan alat Visible Spectroscopy dan Inductively Coupled Plasma-Atomic Emission Spectroscopy (ICP-AES) serta titrasi pada 6 sampel yang telah dipilih. Pengukuran dengan Visible Spectroscopy dilakukan untuk mengukur konsentrasi $\mathrm{SiO}_{2}$. Pengukuran dengan Inductively Coupled Plasma-Atomic Emission Spectroscopy (ICP-AES) dilakukan untuk mengukur konsentrasi $\mathrm{Li}, \mathrm{B}$, dan $\mathrm{Ca}$. Pengukuran secara titrasi dilakukan untuk mengukur konsentrasi $\mathrm{Cl}$.

\subsubsection{Pengolahan dan Analisis Data}

Data konsentrasi unsur $\mathrm{Na}, \mathrm{K}$, dan $\mathrm{Mg}$ dari 12 sampel yang telah diketahui kemudian diolah dan diplot pada diagram segitiga Na-K-Mg dengan menggunakan software XLSTAT. Data konsentrasi Cl, Li, dan B dari 6 sampel yang telah dipilih kemudian diolah dan diplot pada diagram segitiga Cl-Li-B dengan menggunakan software XLSTAT. Kedua diagram tersebut digunakan untuk mengetahui karakteristik fluida panas bumi. Selain itu, kedua diagram juga digunakan untuk menentukan geotermometer yang sesuai pada daerah penelitian. Konsentrasi $\mathrm{SiO}_{2}, \mathrm{Na}, \mathrm{K}$, dan $\mathrm{Ca}$ dimasukkan dalam persamaan geotermometer yang sesuai untuk mengestimasi temperatur reservoir panas bumi. Persamaan geotemometer yang digunakan harus memperhatikan unsur dominan pada air panas tersebut. Data kemudian dianalisis dan dihubungkan dengan potensi panas bumi berdasarkan karakteristik fluida dan temperatur reservoir panas bumi.

\section{HASIL DAN DISKUSI}

\subsection{Karakteristik Reservoir}

\subsubsection{Diagram Segitiga Na-K-Mg}

Berdasarkan diagram segitiga Na-K-Mg (Gambar 2) didapatkan data bahwa semua sampel terdapat di bagian immature water dan memiliki kadar Mg yang lebih tinggi daripada kadar $\mathrm{Na}$ dan K. Sampel pada immature water menandakan bahwa air panas di daerah penelitian tidak mencapai kesetimbangan atau telah mengalami reaksi dengan unsur lain saat 
menuju ke permukaan. Menurut Nicholson (1993) kadar Mg yang tinggi menandakan bahwa air panas bumi telah mengalami pencampuran dengan air meteorik atau air tanah yang memiliki konsentrasi $\mathrm{Mg}$ yang lebih tinggi. Konsentrasi Mg pada fluida panas bumi bertemperatur tinggi atau langsung dari reservoir panas bumi tanpa pengenceran adalah 0,001 ppm-0,1 ppm.

Semua sampel yang terdapat di bagian immature water menyebabkan estimasi temperatur reservoir panas bumi lebih baik menggunakan persamaan geotermometer silika. Berdasarkan diagram segitiga $\mathrm{Na}-\mathrm{K}-\mathrm{Mg}$, geotermometer Na-K lebih cocok digunakan pada sampel yang berada mendekati daerah full equilibrium. Geotermometer $\mathrm{K}-\mathrm{Mg}$ lebih cocok digunakan pada daerah partial equilibrium dan geotermometer silika lebih cocok digunakan pada daerah immature water (Zhang dkk, 2014). Oleh sebab itu, estimasi temperatur reservoir panas bumi di sekitar Gunung Talang lebih baik menggunakan persamaan geotermometer silika. Menurut Aribowo (2011) estimasi temperatur reservoir yang baik tetap harus mempertimbangkan unsur lain yang ada pada fluida reservoir terutama fluida yang telah mengalami pengenceran dan keadaan manifestasi panas bumi tersebut. (Aribowo, 2011).

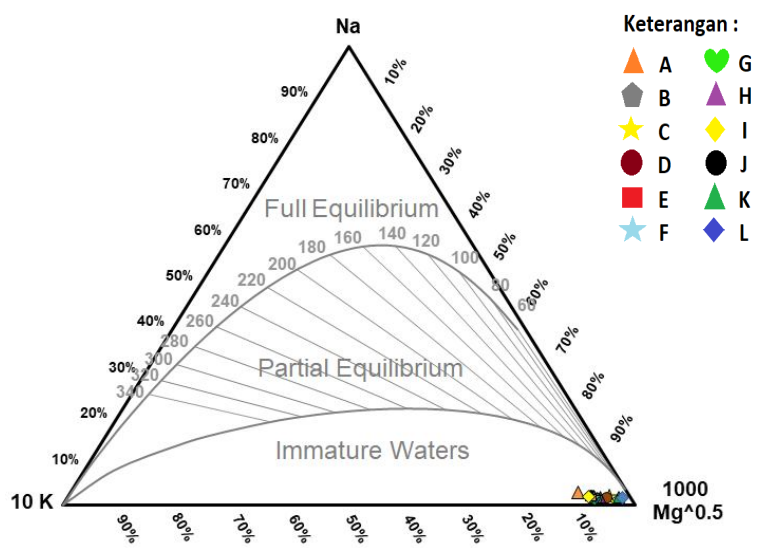

Gambar 2 Hasil plot diagram segitiga Na-K-Mg dimana seluruh titik mata air panas berada pada daerah immature water

\subsubsection{Diagram segitiga Cl-Li-B}

Berdasarkan diagram segitiga Cl-Li-B (Gambar 3) didapatkan kadar B lebih tinggi daripada kadar $\mathrm{Cl}$ dan $\mathrm{Li}$. Hal tersebut menandakan bahwa fluida panas bumi di daerah penelitian berasal dari sistem hidrotermal baru. Daerah penelitian yang terdapat di sekitar Gunung Talang dan memiliki kadar B yang cukup tinggi menandakan bahwa fluida panas bumi dipengaruhi oleh magma Gunung Talang tetapi telah terjadi pengenceran pada fluida reservoir panas bumi saat menuju ke permukaan. Selain itu, kadar B yang cukup tinggi mengindikasikan bahwa fluida panas bumi berinteraksi dengan batuan sedimen yang kaya organik.

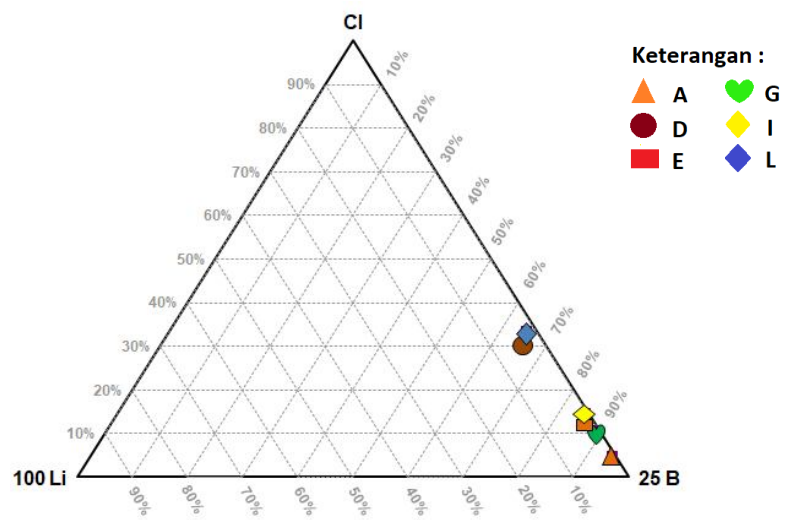

Gambar 3 Hasil plot diagram segitiga Cl-Li-B dimana seluruh titik mata air panas berada pada dominan $\mathrm{B}$ 
Rasio B/Li pada 6 sampel sangat tinggi yaitu 64,58-941,17. Hal tersebut menandakan bahwa fluida panas bumi tersebut keluar ke permukaan bumi melalui zona outflow. Rasio B/Li dapat digunakan untuk menentukan zona upflow atau outflow fluida panas bumi (Nicholson, 1993). Fluida panas bumi keluar melalui zona outflow menandakan bahwa fluida pada daerah tersebut didominasi oleh air. Manifestasi di sekitar Gunung Talang yang banyak sumber mata air panas dan memiliki pH mendekati netral 6,7-7,9 memperkuat indikasi bahwa sistem panas bumi daerah tersebut didominasi oleh air. Pendidihan fluida reservoir panas bumi di sekitar Gunung Talang diperkirakan terjadi di bawah permukaan bumi hingga kedalaman sekitar 150 meter di bawah permukaan bumi.

\subsection{Estimasi Temperatur Reservoir Panas Bumi}

Sampel yang berada di daerah immature water membuat geotermometer yang sesuai untuk ke-6 sampel adalah geotermometr silika. Geotermometer silika telah dikembangkan oleh beberapa ahli. Pemakaian geotermometer silika harus mempertimbangkan karakteristik dari manifestasi panas bumi yang ada pada sampel. Geotermometer amorphous silica tidak cocok digunakan diduga karena kandungan sinter silika yang tidak dominan terdapat di sekitar mata air panas di daerah penelitian. Geotermometer silika chalcedony, opal, dan cristobalite juga tidak cocok digunakan pada daerah penelitian karena kandungan silika daerah tersebut sangat rendah. Geotermometer silika quartz-no steam loss tidak cocok digunakan pada daerah penelitian karena hasil estimasi temperatur reservoir pada daerah I dan L lebih kecil dari temperatur permukaan. Geotermometer silika quartz-maximum steam loss pada $100^{\circ} \mathrm{C}$ juga tidak cocok digunakan karena temperatur reservoir pada daerah I lebih kecil dari temperatur permukaan. Pada penelitian didapatkan temperatur permukaan sebesar $37,1^{\circ} \mathrm{C}-55,0^{\circ} \mathrm{C}$. Oleh sebab itu, geotermometer silika yang cocok digunakan di sekitar Gunung Talang adalah geotermometer silika quartz atau geotermometer kuarsa.

Geotermometer quartz yang dikembangkan oleh Arnorsson pada tahun 1985 dibuat berdasarkan pertimbangan keadaan manifestasi panas bumi. Arnorsson (1985) menyatakan bahwa geotermometer tersebut lebih baik digunakan pada manifestasi sumber mata air hangat. Hal tersebut hampir sesuai dengan temperatur permukaan yang ada di daerah penelitian yang memiliki temperatur permukaan $37,1^{\circ} \mathrm{C}-55,0^{\circ} \mathrm{C}$. Meskipun terdapat beberapa temperatur permukaan mata air panas bumi yang lebih dari $50^{\circ} \mathrm{C}$, akan tetapi perbedaan tersebut tidak terlalu besar, sehingga persamaan geotemometer quartz yang lebih cocok pada daerah penelitian adalah geotemometer quartz yang dikembangkan oleh Arnorsson daripada Geotermometer quartz yang dikembangkan oleh Fournier dan Potter.

Tabel 2 Estimasi temperatur dengan geotermometer silika

\begin{tabular}{|c|c|c|c|c|c|c|c|}
\hline \multirow{2}{*}{$\begin{array}{c}\text { Geotermometer } \\
\text { Silika }\end{array}$} & \multirow[b]{2}{*}{ Referensi } & \multicolumn{6}{|c|}{ Estimasi Temperatur Reservoir $\left({ }^{\circ} \mathrm{C}\right)$} \\
\hline & & $\mathbf{A}$ & D & $\mathbf{E}$ & $\mathbf{G}$ & I & $\mathbf{L}$ \\
\hline $\begin{array}{c}\text { Quartz-no steam } \\
\text { loss } \\
\end{array}$ & Fournier (1977) & 71,98 & 61,31 & 48,75 & 55,14 & 46,68 & 43,09 \\
\hline $\begin{array}{c}\text { Quartz-maximum } \\
\text { steam loss at } \\
100^{\circ} \mathrm{C} \\
\end{array}$ & Fournier (1977) & 76,51 & 67,05 & 55,82 & 61,55 & 53,98 & 50,73 \\
\hline Quartz & $\begin{array}{c}\text { Fournier and Potter } \\
\text { (1982) }\end{array}$ & 156,80 & 145,82 & 132,51 & 139,35 & 130,27 & 126,33 \\
\hline Quartz & Arnorsson (1985) & 179,77 & 168,40 & 154,29 & 161,59 & 151,88 & 147,63 \\
\hline Chalcedony & Fournier (1977) & 122,26 & 108,24 & 91,91 & 100,21 & 89,24 & 84,61 \\
\hline Chalcedony & Arnorsson (1983) & 43,41 & 32,86 & 20,52 & 26,80 & 18,50 & 14,99 \\
\hline Cristobalite & Fournier (1977) & 22,46 & 12,25 & 0,33 & 6,39 & $-1,61$ & $-4,99$ \\
\hline Opal & Fournier (1977) & $-22,24$ & $-31,63$ & $-42,52$ & $-37,00$ & $-44,30$ & $-47,37$ \\
\hline Amorphous silica & Fournier (1977) & $-39,06$ & $-47,79$ & $-57,92$ & $-52,78$ & $-59,57$ & $-62,44$ \\
\hline
\end{tabular}

Berdasarkan geotermometer quartz, semua daerah penelitian memiliki estimasi temperatur reservoir sebesar $147,63 \mathrm{oC}-179,77 \mathrm{oC}$ seperti pada Tabel 2, yang termasuk pada sistem bertemperatur sedang. Fluida panas bumi yang tergolong bertemperatur sedang karena 
telah mengalami banyak pengenceran menuju permukaan bumi tetap membuat sistem panas bumi di daerah penelitian masih bisa digunakan sebagai pengembangan pembangkit listrik tenaga panas bumi. Menurut Saptadji (2009) sistem panas bumi bertemperatur tinggi dan sedang dapat digunakan sebagai pembangkit listrik tenaga panas bumi. Akan tetapi, masih dibutuhkan penelitian lebih lanjut untuk memutuskan kelayakan daerah penelitian sebagai daerah pengembangan pembangkit listrik panas bumi seperti besarnya potensi dan cadangan panas bumi, kedalaman reservoir, dan lainnya.

\section{KESIMPULAN}

Semua mata air panas penelitian di sekitar Gunung Talang berada di zona immature water pada diagram segitiga Na-K-Mg. Hal tersebut menandakan bahwa fluida panas bumi di daerah penelitian telah mengalami pengenceran ketika menuju permukaan bumi. Fluida panas bumi di sekitar Gunung Talang diindikasi berasal dari sistem hidrotermal baru dan mata air panas keluar dari zona outflow dari analisis diagram segitiga Cl-Li-B. Pendidihan fluida panas bumi diindikasi berada di bawah permukaan bumi hingga kedalaman sekitar 150 meter. Estimasi temperatur reservoir dengan menggunakan geotermometer silika quartz yang dikembangkan oleh Arnorsson menghasilkan estimasi temperatur $147,63^{\circ} \mathrm{C}-179,77^{\circ} \mathrm{C}$ yang berada pada temperatur sedang. Hal tersebut menandakan sistem panas bumi di sekitar Gunung Talang dapat digunakan untuk pengembangan pembangkit listrik tenaga panas bumi.

\section{DAFTAR PUSTAKA}

Aribowo, Y., "Prediksi Temperatur Reservoir Panas Bumi dengan Menggunakan Metoda Geotermometer Kimia Fluida", Teknik, 32, 234-238 (2011).

Armstead, H. dan Christopher, H., "Geothermal Energy: Its Past, Present and Future Contribution to the Energy Needs of Man”, E. \& F.N Spon, New York, 1983.

Arnorsson, "The Use of Mixing Models and Chemical Geothermometers For Estimating Underground Temperatures in Geothermal Systems", Journal of Vilcanology and Geothermal Research, 23, 299-335 (1985).

Aulia, M.Z., "Karakterisasi Sistem Panas Bumi "TP" dengan Analisis Data Geokimia dan Model Magnetotellurik untuk Menentukan Lokasi Titik Bor Eksplorasi”, Skripsi, Universitas Lampung, 2014.

Direktorat Panas Bumi Kementerian Energi dan Sumber Daya Mineral Indonesia, "Potensi Panas Bumi Indonesia Jilid 1", Kementerian Energi dan Sumber Daya Mineral, Jakarta, 2017.

Giggenbach, W. F., "Chemical Techniques in Geothermal Exploration", Application of Geochemistry In Geothermal Reservoir Development, 119-142, (1991).

Giggenbach, W. F., "Geothermal Solute Equilibria. Derivation of Na-K-Mg-Ca geoindicators", Application Of Geochemistry In Geothermal Reservoir Development, 2749-2765, (1988).

Munandar, A., Suhanto, E., Kusnadi, D., Idral, A., dan Solviah, M., "Penyelidikan Terpadu Daerah Panas Bumi Gunung Talang Kabupaten Solok - Sumatera Barat", Kolokium Hasil Kegiatan Inventarisasi Sumber Daya Mineral - DIM, SUBDIT Panas Bumi (2003), 1-7.

Naryanto, H. S., "Kegempaan di Daaerah Sumatera", Alami, 2, 1-7, (1997).

Nicholson, K., "Geothermal Fluids", Springer Verlag Inc., Berlin, 1993.

Saptadji, N.M., "Teknik Panas Bumi", Departemen Teknik Perminyakan Fakultas Ilmu Kebumian dan Teknologi Mineral Institut Teknologi Bandung, Bandung, 2009.

Sismanto dan Andayany, "Pengembangan Persamaan Geotermometer Empiris untuk Estimasi Suhu Reservoir Sumber Mata Air Panas", Prosiding Pertemuan Ilmiah XXVI HFI Jateng \& DIY, Purworejo (2012).

Zhang, X., Guo, Q., Li, J., Liu, M., Wang, Y., dan Yang, Y., "Estimation Of Reservoir Temperature Using Silica And Cationic Solutes Geothermometers: A Case Study In The Tengchong Geothermal Area", Springer, China University of Geosciences, 34, 233-240, (2007). 
Website Dinas Pertambangan dan Energi Provinsi Sumatera Barat, 2017, www.sumbarprov.go.id diakses Maret 2018. 